\title{
CORRECTION
}

\section{Correction to: A system based on Hadoop for radar data analysis}

\author{
Chi Yang ${ }^{1,2} \cdot$ Xiaomin Yang $^{1} \cdot$ Feng Yang ${ }^{2}$ \\ (c) Springer-Verlag GmbH Germany, part of Springer Nature 2020

\section{Correction to:} \\ Journal of Ambient Intelligence and Humanized \\ Computing (2019) 10:3899-3913 \\ https://doi.org/10.1007/s12652-018-0980-3
}

The below affiliation for author Chi Yang was missed to be included in the original article.

The affiliation is as follows:

"Science and Technology on Electronic Information Control Laboratory, Chengdu 610036, China".

Publisher's Note Springer Nature remains neutral with regard to jurisdictional claims in published maps and institutional affiliations.

The original article can be found online at https://doi.org/10.1007/ s12652-018-0980-3.

Xiaomin Yang

arielyang@scu.edu.cn

1 College of Electronics and Information Engineering, Sichuan University, Chengdu 610064, Sichuan, China

2 Science and Technology on Electronic Information Control Laboratory, Chengdu 610036, China 